\title{
A HISTÓRIA DOCUMENTAL DA PRIMEIRA REPÚBLICA.
}

\author{
JOSE ROBERTO DO AMARAL LAPA \\ da Faculdade de Filosofia, Ciências e Letras de Marilia (SP).
}

$O$ avanço e a complexidade que, devido a êsse mesmo iranço, atingiram os meios de comunicação em nossos dias, objetivando compreender cada vez de maneira mais ampla e persuasiva a massa, e nela o indivíduo, através de imensa variedade de técnicas, não afetaram por enquanto, pelo menos decisivamente, a importância do texto documental de interêsse para a História.

Isto significa que, se o elenco de fontes históricas aumentou de maneira impressionante e o volume de informações cresceu ao ponto de sufocar o historiador na sua busca seletiva para a compreensão histórica, o texto documental, ou o texto como fonte, conseguiu até então resguardar o seu devido lugar, por mais diversas que tenham sido as maneiras, as técnicas ou os instrumentos de que se serviu o homem para a sua redação.

Entretanto, diante dessa impressionante massa de informações tem assistido ao historiador, cada vez de maneira mais angustiante, uma tarefa preliminar que, em boa parte, dirige-se mais para a computação de dados e a elaboração de esquemas que permitam digerir o acervo documental, traduzindo-o, sintetizando-o ou interpretando-o para colocá-lo em condições de ser analisado.

E bem possível até que a História, num certo momento futuro, se desvencilhe de tal maneira do texto documento, que ela será redigida apesar do documento, muito ao contrário portanto da nossa antiga convicção recebida nos bancos escolares de que sem o documento não há História. E claro que nos referimos ao texto como documento fonte tradicional para o historiador, mas cuja apresentação e transmissão de informações têm sofrido revolucionárias trunsformações, sobretudo ditadas pelas conquistas eletrônicas que levarão o 
historiador forçosamente a adotar processos diversos de memorização, armazenamento e utilização das informações computadas (1) .

Essa perspectiva diminui até de significação quando verificamos a conclusão de alguns filósofos da História que afirmam que a História está com os seus dias contados...

De qualquer maneira, estamos em pleno processo de profundas alterações diante as quais é difícil ainda ter uma noção clara do futuro sistema de trabalho do historiador no que diz respeito aos seus instrumentos, às fontes de que se utilizará, à sua própria participação ou à finalidade mesma da História.

Esse tributo que o historiador e a História pagam ao progresso tecnológico e científico que não foram conquistados para êle, historiador, e por isso mesmo não podem ser muitas vêzes acompanhados por êle, oferece no entanto, em contrapartida, novos recursos no que diz respeito à conservação e utilização da massa de informações, no que naturalmente se incluem os dados estatísticos.

Assim, não é que a História procure libertar-se do atrativo dominante e até algum tempo atrás decisivo do texto como documento, pois o historiador, utilizando-se do documento, procura ver através do documento, iluminando-o, dando-lhe vida, procurando saber além da verdade e da certeza que o documento pode ou não encerrar.

Nessa quantidade de documentos que tanto se avoluma, alguns se sobressaem por diversos motivos, entre os quais: 1). - foram redigidos em momentos decisivos do processo histórico; 2). - quem os redigiu teve um papel destacado nos acontecimentos históricos; $3)$. - o texto redigido por um indivíduo ou por um grupo teve implicações de importância, sem que muitas vêzes essas implicações necessàriamente estivessem nas intenções ou fôssem previstas pelos seus autores no ato da redação ; 4). - oferecem pela sua frequiência a oportunidade do estabelecimento de médias de compreensão de determinados fenômenos; 5). - foram redigidos para expressar importantes decisões de indivíduos ou grupos, do Poder constituído ou de instituições, decisões que tiveram longa duração, largo alcance e profundas conseqüências e 6). - fornecem informações ou dados, descrevendo situações ou interpretando-as de maneira a permitir o alcance e a compreensão das mudanças sociais, políticas e econômicas, epidérmicas ou profundas. E' natural que essas características que

(1). - Sôbre a aplicação dos computadores à pesquisa histórica é de crande interésse o levantamento bibllográfico periódico que vem publicando o boletim do Queens College da Universidade da Cidade de New Ycrk, em cujo número 3 (Vol. 3), correspondente a janeiro de 1969, temos o artigo de Charles M. Dollar, Innovation in Historical Research: A Computer Approach. 
podem definir a qualidade do documento e portanto o seu interêsse para o historiador possam ocorrer mais de uma delas num mesmo texto.

Para a historiografia brasileira contemporânea que se preocupa, em alguns centros de estudo, cada vez mais com a interpretação do coetâneo, procurando "ver" além do fato e do personagem histórico na sua ação, buscando a compreensão dos sistemas e regimes políticos, sociais a econômicos, o que equivale a dizer discernindo o que é estrutural do que é circunstancial ou conjuntural, sem que haja necessàriamente uma hierarquização nessa distinção, para essa historiografia o texto documental parece sofrer gradativamente a redução das proporções de sua importância. Mas é claro que mesmo a esta redução sobrenadam certos textos que, ainda que se releve a grande distância que há geralmente entre a realidade descrita ou sugerida no texto e a realidade histórica em que êle se insere ou a que êle se refere, apresuntam-se como fontes indispensáveis de consulta e análise.

Estas reflexões vêm a propósito do oportuno lançamento de uma coletânea de textos básicos para a história do que se convencionou chamar entre nós de Primeira República (2).

Assim como as bibliografias e os repertórios de leis, a putlicação de textos documentais só de uns anos para cá parece estar merecendo interêsse das editôras comerciais, o que de certa maneira revela maior grau de maturidade do pensamento histórico brasileiro ao lado da constatação da existência de um público leitor para tal tipo de antologia .

Ambos, estudiosos e estudantes, devem encontrar nesses trabalhos de pesquisa e divulgação instrumentos indispensáveis para a racionalização dos seus estudos, dando-lhes mais altos padrões científicos de trabalho, o que em outros países há muito foi dignificado como tarefa preliminar e de indispensável importância (3).

(2). - EDGARD CARONE, A Primeira Repuiblica (1889-1930. Texto e contexto), 29 da Coleção "Corpo e Alma do Brasil", Difusăo Européia do Livro, São Paulo, maio de 1969.

(3) - - Como antologia geral de textos básicos para a História do Brasil, o que de melhor conhecemos fol felto por um professor norte-americano para atender naturalmente o interêsse dos estudiosos daquele país e portanto com limitaçóes para o leitor braslieiro, conforme $A$ Documentary History of Brazil reunido por E. Bradford Burns e editado por Alfred A. Knofp, New York, 1966. Recentemente fol lançada a História Documental do Brasil, de autoria da Profa. Terezinha de Castro, Distribuidora Record, Rlo, 1968, que ainda não tivemos ocasiáo de examinar. Ainda em boa ptrte para o período que Edgard Carone balizou para sua antologia, pelo número e importância dos documentos transcritos merece referência o conjunto de obras de Hélío Silva denominado "O ciclo de Vargas" (1922. Sangue na areia de Copacabana; 1926. A grande marcha; 1930. A revoluçäo traida; 1931. Os tenentes no poder; 1932. A guerra paulista e 1933. A crise do tenentismo, todos editados pela Editôra Civillzação Brasileira, Riol. Sabe- 
Criteriosamente Edgard Carone conseguiu reunir os documentos de um período recente da História do Brasil, durante o qual se pronuncia de maneira mais enfática a irreversibilidade das transformações que em determinadas áreas do país marcam as suas contradições e os rumos da revolução. E' quando verificamos o antigo dualismo estrutural: o meio rural com a grande propriedade, a massa amor$\mathrm{fa}$, a aristocracia fechada, a fôrça político-policial das oligarquias locais se contrapondo ao nseio urbano com a massa operária ativa e reivindicante, as classes médias e a nova burguesia empresarial ligada à indústria, ambos, rural e urbano, pautando o comportamento dos grupos pelas imposições do capitalismo dependente, condicionado às pressões externas que se fazem sentir direta ou indiretamente tanto para a fazenda como emprêsa agrícola, como para a fábrica como emprêsa industrial.

E' o Brasil Arcaico em luta com o Brasil Moderno. Aquêle mais onerado pelo preço que êste lhe cobrou e lhe cobra pela sua industrialização, isto é, a migração interna para atender à demanda da mão-de-obra rural e o mercado profissional urbano mais jigado à prestação de serviços e aos escalóes inferiores da qualificação profissional exigida pelo complexo industrial, além do natural sistema de articulação da matéria-prima com a manufatura entre as áreas de economia agrária e de subsistência, como o Norte e o Nordeste, e as de industrialização em desenvolvimento como eram o Leste e o Sul.

Assim, nesses quarenta anos que correspondem à Primeira República, desenvolve-se um longo e muitas vêzes penoso ensaio político de justaposição das classes e instituições ao desenvolvimento do capitalismo industrial.

Esse processo de acomodação não se faz sem conflitos, pois o dualismo entre a resistência rural e o avanço reivindicatório urbano, o comportamento interveniente do Estado, muitas vêzes sem a suficiente cobertura político-militar para impor seu poder às fôrças políticas e econômicas locais, bem como o fortalecimento de novos grupos atuantes no meio urbano, gerarão áreas de atrito, cujo desenlace será um movimento armado de maior envergadura que resultará por sua vez numa revolução que chegará a afetar certas estruturas, apesar da inércia da massa rural e ainda da quase indiferença geral do povo, fàcilmente verificáveis em diferentes episódios. Uma ánálise

mos ainda que o Prof. José Honório Rodrigues prepara uma História Moderna do Brasil, na qual será dada especial atenção à documentação básica para o entendimento do Brasil Moderno. 
sincrônica nos convencerá sempre que êsses embates se travaram ritmados por condicionantes internos e externos.

Mas, o valor da antologia em questão está na visão de conjunto que nos permite no tempo e no espaço, mostrando os diversos componentes dêsse processo de transformações dos 41 anos compreendidos pela Primeira República.

Feita por um historiador, a coletânea reune o conjunto documental que faltava para o estudo daquele período e que possibilitará tentativas de síntese até agora elaboradas com generalização e explicações parciais sobretudo por alguns cientistas sociais.

Com êsses documentos que ambiciosamente abarcam a cronologia fatual da política e sua movimentação, a estrutura agrária e a industrial, as classes sociais e o papel do exército, torna-se possível verificar as dimensões da luta pelo Poder com suas pressões de diferente ordem que irão desembocar na revolução de 1930 (4).

Reclamar omissões de uma antologia, seja ela qual fôr, é vêzo a que não podemos fugir, daí verificarmos a ausência da história cultural, isto é, de alguns documentos básicos para a compreensão pelo menos de um movimento de renovação nas letras e nas artes, cujas raízes e manifestações datam justamente dêsse período: o Mcdernismo. Para tanto acreditamos que o Manifesto Antropófago de Oswald de Andrade, publicado na Revista de Antropofagia, ano I, $\mathrm{n}^{\circ} 1$, de maio de 1928, corresponderia perfeitamente, ao que aliás também podia juntar-se o Manifesto da poesia pau-brasil, do mesmo Oswald, publicado no Correio da Manhã, do Rio, de 18 de março de 1924.

$\mathrm{Na}$ área institucional, além do Exército, o comprometimiento e a ação da Igreja acreditamos que merecessem também alguns textos esclarecedores. O Decreto de 7 de janeiro de 1890 , por exemplo, separando a Igreja do Estado seria um dêles. Não mais do que isso.

(4). - Para o estudo dos movimentos revoluctonários justamente dêsse perfodo uma sintese que se recomenda é o livro anterior de Edgard Carone, Revoluçōes do Brasil Contemporaneo (1922-1938), Coleçăo Buriti, vol. 11, Editôra Desa, Săo Paulo, 1965. 